\title{
Subnanoliter enzymatic assays on microarrays
}

\author{
Philipp Angenendt, Hans Lehrach, Jürgen Kreutzberger and Jörn Glökler
}

Max Planck Institute for Molecular Genetics, Berlin, Germany

\begin{abstract}
Many areas of research today are based on enzymatic assays most of which are still performed as enzyme-linked immunosorbent assays in microtiter plates. The demand for highly parallel screening of thousands of samples eventually led to a miniaturization and automation of these assays. However, the final transfer of enzymatic assays from a microtiter-based technology to microarrays has proven to be difficult for various reasons, such as the inability to maintain unbound reaction products on the spot of reaction or the missing capability of multiplexing. Here, we have conducted multiplex enzymatic assays in subnanoliter volumes on a single microarray using the multiple spotting technology. We were able to measure enzymatic activity with a sensitivity down to 35 enzyme molecules, applying only conventional flat microarray surfaces and standard microarray hardware. We have performed assays of inhibition and applied this format for the detection of prognostic markers, such as cathepsin D. The new approach allows the rapid and multiplex screening of thousands of samples on a single microarray with applications in drug screening, metagenomics, and high-throughput enzyme assays.
\end{abstract}

\section{Keywords:}

Drug screening / Enzymatic assay / Metagenomics / Multiple spotting technique / Protein microarray

\section{Introduction}

The investigation of enzymatic reactivity is an important part of current proteomics research, with diverse areas of application, such as the identification and localization of enzymes within the cellular network, screening of drug candidates, development of diagnostic assays as well as optimization of enzymatic function through mutagenesis. Since many of these applications require high-throughput analysis with minimal consumption of the precious samples, the transfer of such assays to microarrays is desirable [1]. Several investigations regarding the transfer of enzymatic assays to nanowells and microarrays have been performed, which predominantly describe the enzymatic phosphorylation of pep-

Correspondence: Dr. Philipp Angenendt, DKFZ, Functional Genome Analysis, Im Neuenheimer Feld 580, D-69120 Heidelberg, Germany

E-mail: p.angenendt@dkfz-heidelberg.de Fax: +49-6221-42-4687

Abbreviations: AP, alkaline phosphatase; dd, double-distilled; $\boldsymbol{\beta}$-gal, $\beta$-galactosidase; HRP, horseradish peroxidase; MIST, multiple spotting technology; PETG, 2-phenylethyl $\beta$-D-thiogalactoside tides and proteins by kinases [2-5]. Additionally, cell-free expression and analysis of green fluorescent protein and $\beta$ galactosidase ( $\beta$-gal) in nanowells has been performed [6] as well as indirect detection of enzymatic activity by mechanism-based suicide inhibitors [7]. In order to maintain unbound reaction products on the spot of reaction, Gosalia and co-workers [8] spotted chemical compounds in nanoliter droplets on flat surfaces and applied the enzyme solution on top by aerosol deposition. Schweitzer and colleagues $[9,10]$ described a new methodology named Rolling Circle Amplification for signal amplification on microarrays, which relies on enzymatic extension of an primer-antibody conjugate followed by hybridization of labeled probes to the generated DNA strand. As an alternative approach to fluorescent detection, Huang and colleagues [29] applied chemiluminescence for the sensitive detection of multiple cytokines. However, all currently presented solutions either lack the possibility of multiplex screening of analytes against enzymes, or require complicated liquid handling, surface modifications, and additional equipment.

\footnotetext{
* Additional corresponding author: Dr. Jörn Glökler, E-mail: gloekler@ma-network.com
} 


\section{Material and methods}

Polystyrene cell culture slides were purchased from Nalge Nunc (Rochester, NY, USA) and Amplex ${ }^{\circledR}$ Red Hydrogen Peroxide/Peroxidase Assay Kit, BODIPY TR casein as part of the EnzChek ${ }^{\circledR}$ Protease Assay Kit (red fluorescence), 9H(1,3-dichloro-9,9-dimethylacridin-2-one-7-yl) phosphate as well as phenylethyl- $\beta$-D-thiogalactopyranoside were purchased from Molecular Probes (Leiden, The Netherlands). Alkaline phosphatase (AP) and resofurin $\beta$-D-galactopyranoside were obtained from Sigma-Aldrich (Munich, Germany), $\beta$-galactosidase from Fluka (Buchs, Switzerland) and bovine kidney cathepsin D was obtained from Calbiochem (San Diego, CA, USA).

\subsection{Assay of inhibition for horseradish peroxidase}

All components of this assay with the exception of the sodium azide and the polystyrene cell culture slides were part of the Amplex $^{\circledR}$ Red Hydrogen Peroxide/Peroxidase Assay Kit. Stock solutions (10 mM) of the fluorogenic substrate 10-acetyl3,7-dihydroxyphenoxazine were prepared as described by the manufacturer. The stock solution was diluted down to $100 \mu \mathrm{M}$ using $1 \mathrm{x}$ reaction buffer and spotted onto polystyrene cell culture slides using a QArray spotting robot (Genetix, New Milton, Hampshire, UK) equipped with $16 \times 150 \mu \mathrm{m}$ solid steel pins. Horseradish peroxidase (HRP) and $\mathrm{H}_{2} \mathrm{O}_{2}$ stock solutions were diluted as described by the manufacturer and two aliquots of enzyme solution containing $0.2 \mathrm{U} / \mathrm{mL}$ HRP in $20 \mu \mathrm{M} \mathrm{H}_{2} \mathrm{O}_{2}$ and $8.7 \% \mathrm{v} / \mathrm{v}$ glycerol diluted in $1 \mathrm{x}$ reaction buffer were generated, one with and one without $1 \% \mathrm{w} / \mathrm{v}$ sodium azide. Both aliquots were spotted at room temperature in sets of 32 spots per aliquot onto the fluorogenic substrate and on a part of the slide without substrate. The slides were scanned directly after spotting using a ScanArray 4000 scanner (Perkin Elmer, Wellesley, MA, USA). After scanning, the slides were placed in a dark, humidified chamber and incubated at $37^{\circ} \mathrm{C}$ for $2 \mathrm{~h}$. The slides were scanned again using the same settings and analyzed using the GenePix Pro 4.1 software (Axon Instruments, Union City, CA, USA).

\subsection{Determination of the detection limit for horseradish peroxidase}

The determination of the detection limits was performed as in the assay of inhibition described in a Section 2.1 with the following exceptions: The fluorogenic substrate was dissolved to a concentration of $10 \mu \mathrm{m}$ in double-distilled (dd) $\mathrm{H}_{2} \mathrm{O}$. Dilution steps of HRP ranging from 16755 to 0 molecules per spot were prepared in $20 \mu \mathrm{M} \mathrm{H}_{2} \mathrm{O}_{2}$ and $8.7 \% \mathrm{v} / \mathrm{v}$ glycerol diluted in $1 \mathrm{x}$ reaction buffer and spotted in sets of 64 replicates per concentration step. Scanning was performed with the same scanner settings directly after spotting and after a $2.5 \mathrm{~h}$ incubation in a dark, humidified chamber at $37^{\circ} \mathrm{C}$. The mean signal intensity of each concentration was calculated and the detection limit (mean $+2 \mathrm{SD}$ ) was determined.

\subsection{Assay of inhibition for alkaline phosphatase}

The fluorogenic substrate 9H-(1,3-dichloro-9,9-dimethylacridin-2-one-7-yl) phosphate (DDAO phosphate) was diluted to a concentration of $5 \mu \mathrm{M}$ using $\mathrm{dd}_{2} \mathrm{O}$ and spotted as described in Section 2.2. In a second spotting step, different concentrations ranging from $10 \mathrm{~mm}$ to $1 \mu \mathrm{M}$ EDTA dissolved in $\mathrm{ddH}_{2} \mathrm{O}$ as well as $\mathrm{ddH}_{2} \mathrm{O}$ alone were spotted in sets of 16 spots onto the immobilized substrate. Enzyme solution was prepared at a concentration of $981 \mathrm{mU} / \mathrm{mL}$ alkaline phosphatase (AP) in AP buffer ( $1 \mathrm{~mm} \mathrm{MgCl}_{2}, 100 \mathrm{~mm}$ Tris- $\left.\mathrm{HCl}, \mathrm{pH} 9.5\right)$ containing $8.7 \% \mathrm{v} / \mathrm{v}$ glycerol and spotted in sets of 16 spots onto the positions of the substrate/EDTA. Scanning analysis was performed directly after spotting as described in Section 2.1.

\subsection{Determination of the detection limits for alkaline phosphatase}

For the detection limit assay, the fluorogenic substrate DDAO phosphate was spotted at a concentration of $5 \mu \mathrm{m}$. In a second spotting step, different amounts of AP ranging from 9433 to 0 molecules per spot were prepared in AP buffer containing $8.7 \% \mathrm{v} / \mathrm{v}$ glycerol and spotted in sets of 64 spots per concentration step onto the immobilized DDAO phosphate. Scanning was performed with the same scanner settings directly after spotting and after a $2 \mathrm{~h}$ incubation in a dark, humidified chamber at $37^{\circ} \mathrm{C}$. The mean signal intensity of each concentration was calculated and the detection limit (mean + 2 SD) was determined.

\subsection{Assay of inhibition for $\beta$-galactosidase}

A stock solution of the fluorogenic substrate resorufin $\beta$-Dgalactopyranoside was prepared with a concentration of $20 \mathrm{mg} / \mathrm{mL}$ using DMSO. Working dilutions of $0.2 \mathrm{mg} / \mathrm{mL}$ were prepared and spotted as described in Section 2.3. Dilutions of 2-phenylethyl $\beta$-D-thiogalactoside (PETG) were prepared ranging from $3.3 \mathrm{~mm}$ to $0.33 \mu \mathrm{M}$ in $\mathrm{dd}_{2} \mathrm{O}$ and spotted in sets of 16 spot per concentration step onto the substrate. In a third spotting step, a $\beta$-gal dilution of $1 \mathrm{U} / \mathrm{mL}$ was prepared in PBS containing $8.7 \% \mathrm{v} / \mathrm{v}$ glycerol and spotted in sets of 16 spots per concentration step. Scanning and analysis was performed directly after spotting.

\subsection{Determination of the detection limits for $\beta$-galactosidase}

The determination of the detection limits was carried out as in the assay of inhibition with the following exceptions: $\beta$-gal dilutions ranging from 42.57 to 0 amol per spot were prepared in PBS containing $8.7 \% \mathrm{v} / \mathrm{v}$ glycerol and spotted in sets of 64 spots per concentration step onto the fluorogenic substrate. Scanning was performed with the same scanner settings directly after spotting and after a $2 \mathrm{~h}$ incubation in a dark, humidified chamber at $37^{\circ} \mathrm{C}$. The mean signal intensity of each concentration was calculated and the detection limit (mean + 2 SD) was determined. 


\subsection{Determination of the detection limit for cathepsin D}

For the determination of the detection limit, a $1 \mathrm{mg} / \mathrm{mL}$ stock solution of BODIPY TR casein was prepared by addition of $200 \mu \mathrm{L}$ sodium citrate buffer ( $\mathrm{pH}$ 3.5). Stock solution was dissolved down to $20 \mu \mathrm{g} / \mathrm{mL}$ BODIPY TR casein using $20 \mathrm{~mm}$ sodium citrate ( $\mathrm{pH} 3.5$ ) containing $8.7 \% \mathrm{v} / \mathrm{v}$ glycerol as buffer and spotted as described in Section 2.1. Dilution steps ranging from 4013 to 0 amol per spot were prepared using $20 \mathrm{~mm}$ sodium citrate $(\mathrm{pH} 3.5)$ containing $8.7 \% \mathrm{v} / \mathrm{v}$ glycerol and spotted as described previously. Scanning was performed directly and after a $1 \mathrm{~h}$ incubation at $37^{\circ} \mathrm{C}$ with the same scanning settings.

\section{Results and discussion}

To demonstrate the principle of multiplex enzymatic assays in subnanoliter volumes on a microarray, different enzymes such as alkaline phosphatase or horseradish peroxidase were tested. The principle of the assays is based on the multiple spotting technology (MIST) $[11,12]$ and comprises two spotting steps in which the fluorogenic substrates are spotted in a first round of spotting, followed by the transfer of enzyme solution in a second round of spotting. Since the enzyme solution contains hygroscopic additives, such as glycerol, the total evaporation of the transferred solution, which is initially about $0.6 \mathrm{~nL}$ [13], is prevented.

One crucial issue for such assays was the choice of an appropriate surface, which should provide a favorable environment for the reaction. In this case, interaction with the surface was considered detrimental for enzymatic reactions, as it was determined that immobilization can compromise functionality of proteins [14]. Three different surfaces were tested, which comprised poly-L-lysine coated slides, BSA coated epoxy slides and polystyrene slides. As all three surfaces proved their applicability for enzymatic assays (data not shown), polystyrene slides were used in all further experiments, being inexpensive and displaying a low binding capacity as determined in previous studies $[15,16]$.

\subsection{Horseradish peroxidase}

The first enzyme tested was HRP, which is one of the most commonly used enzymes for ELISA and catalyzes the oxidation of its substrate by transfer of an oxygen from a donor such as hydrogen peroxide to the substrate. Activity can be inhibited by the addition of sodium azide, which leads to the production of the inactivating azidyl radical [17]. To demonstrate the activity of HRP, an inhibition assay using sodium azide as a specific inhibitor was performed (Fig. 1). To display the time dependence of the enzymatic action, the microarray was scanned directly after spotting (designated as $0 \mathrm{~h}$ ) and after a $2 \mathrm{~h}$ incubation at $37^{\circ} \mathrm{C}$. To show the sensitivity of the reaction, a dilution row of HRP was prepared and spotted in a second spotting step onto the previously deposited fluorogenic substrate. The scanning was performed directly after spotting $(0 \mathrm{~h})$ and after $2.5 \mathrm{~h}$ incubation at $37^{\circ} \mathrm{C}$ (Fig. 2).

Figure 1 clearly demonstrates that the increase of signal intensity is dependent on enzymatic activity. While nearly no signals arise in the inhibited reaction, medium intensity signals can be seen in the uninhibited reaction without incubation, which increase upon incubation at $37^{\circ} \mathrm{C}$. Negative controls lacking the enzyme, which were performed on the same chip, displayed signal intensities that were indistinguishable from background (data not shown). Figure 2 does not display any signal intensities for the dilution row without incubation time, while increasing signal intensities with increasing enzyme concentration can be seen after $2.5 \mathrm{~h}$ incubation with a total detection limit of $0.85 \mathrm{zmol}$ ( $\sim 510$ molecules HRP) per spot.
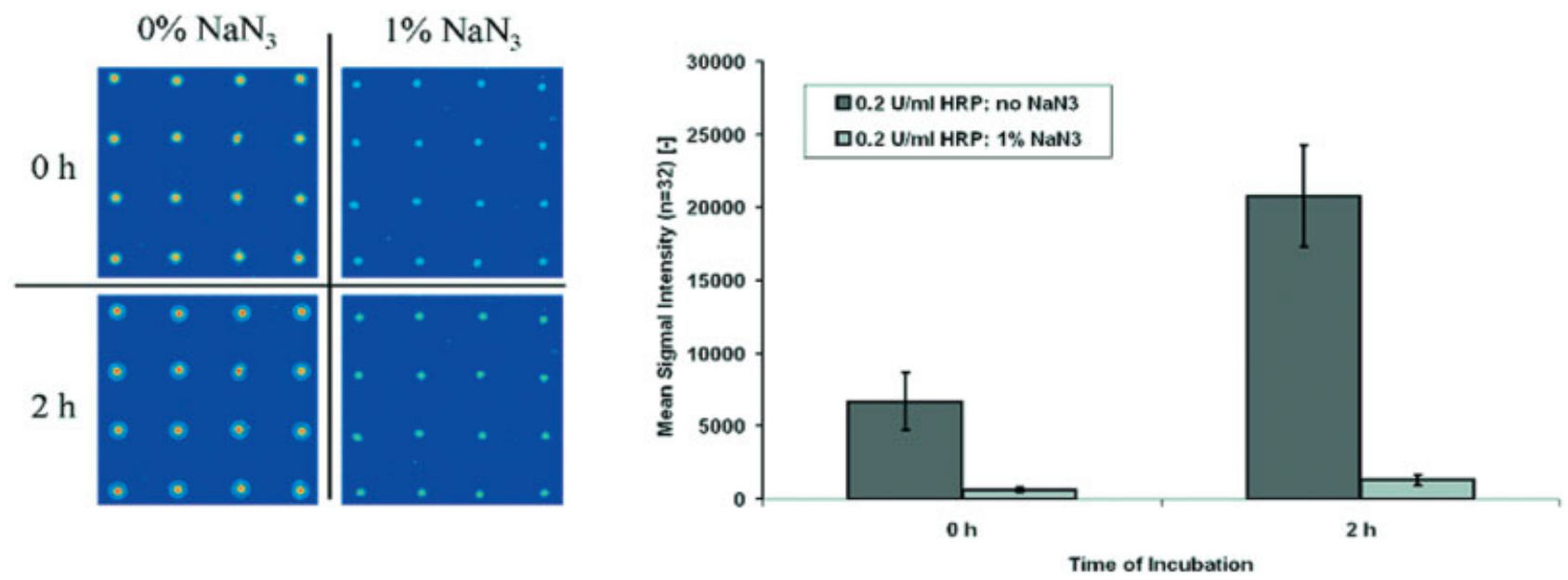

Figure 1. Scans of inhibition assay for HRP and quantification. Left: Two assays were performed using $0.2 \mathrm{mU} / \mathrm{mL} \mathrm{HRP}$, one without and one with $1 \% \mathrm{w} / \mathrm{v} \mathrm{NaN}$. Scanning and analysis was performed without incubation and after $2 \mathrm{~h}$ incubation. Right: Mean signal intensity versus time of incubation diagram with standard deviation error bars for inhibition assay of HRP. Two measurements of the same chip were performed, one directly after spotting, indicated by $0 \mathrm{~h}$ and one after $2.5 \mathrm{~h}$ of incubation. 


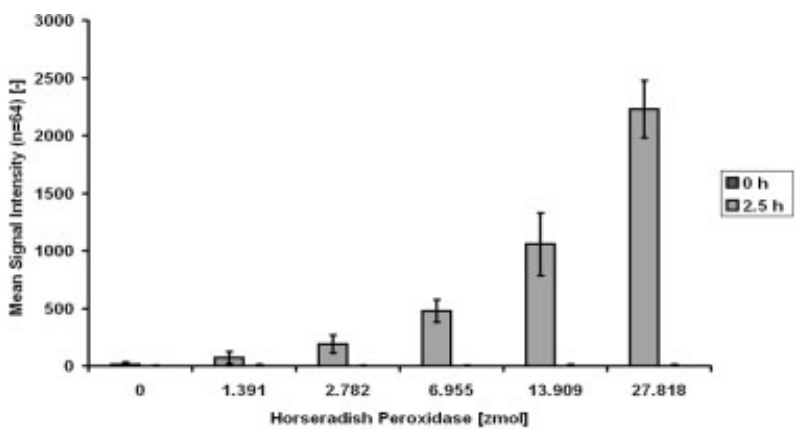

Figure 2. Detection limit assay for HRP. Mean signal intensity versus activity of HRP diagram with standard deviation error bars for the detection limit assay of HRP. A dilution row ranging from 27.8 to 0 molecules HRP per spot was prepared and spotted onto a fluorogenic substrate. Scanning and analysis were performed without incubation and after $2.5 \mathrm{~h}$ incubation.

\subsection{Alkaline phosphatase and $\beta$-galactosidase}

Similar assays to demonstrate the applicability of the multiple spotting technique to enzymes were performed using alkaline phosphatase (AP) and $\beta$-galactosidase ( $\beta$-gal). In contrast to HRP, both enzymes display different activities, with AP catalyzing dephosphorylation and $\beta$-gal catalyzing transgalactosidation. Enzymatic function of AP is hereby mainly regulated by divalent cations as essential activators. Addition of EDTA, which is a well-known chelator of divalent cations, results in complete and irreversible functional block of all AP activity [17]. $\beta$-Gal catalyzes the hydrolysis of terminal, nonreducing $\beta$-D-galactose residues in $\beta$-D-galactosides. PETG is a nonhydrolyzable analog of the $\beta$-D-galactose and is commonly used as a selective and reversible inhibitor of $\beta$ gal $[6,19-21]$. To demonstrate the functionality of both enzymes, AP and $\beta$-gal were subjected to assays of inhibition (Figs. 3 and 5). Moreover, dilution row assays were performed for determination of the detection limits of both enzymes with and without incubation (Figs. 4 and 6).

Figure 3 displays decreasing signal intensity with increasing EDTA concentrations, which proves functionality of AP on the microarray. The determination of the detection

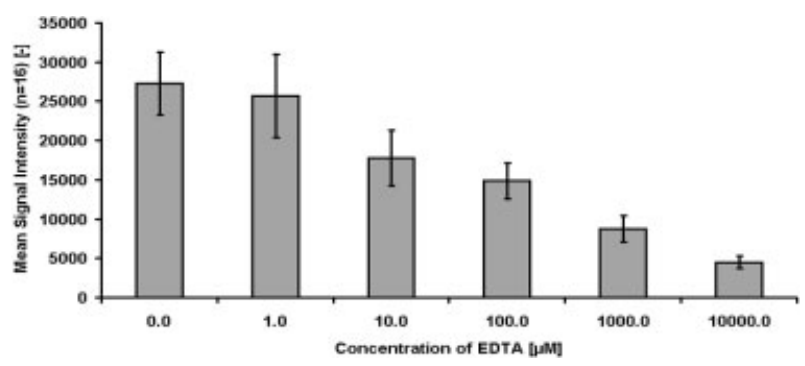

Figure 3. Assay of inhibition for AP. Mean signal intensity versus concentration of EDTA diagram with standard deviation error bars for inhibition assay of AP. A dilution row of EDTA was prepared ranging from $10 \mathrm{~mm}$ to $0 \mathrm{~mm}$ EDTA and applied to a microarray based assay of AP. Scanning and analysis were performed without incubation.

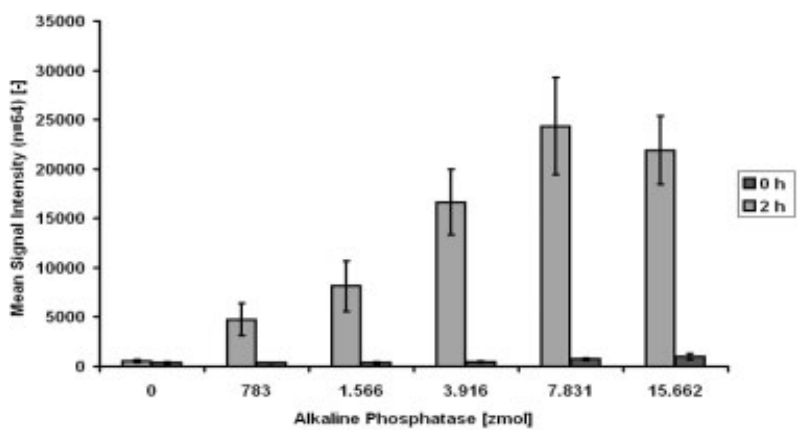

Figure 4. Detection limit assay for AP. Mean signal intensity versus activity of AP diagram with standard deviation error bars for the detection limit assay of AP. A dilution row ranging from 15.6 to 0 molecules AP per spot was prepared and spotted onto a fluorogenic substrate. Scanning and analysis were performed without incubation and after $2 \mathrm{~h}$ incubation.

limit without incubation (Fig. 4) only shows minor signal intensities on the microarray. However, after incubation of the microarray for $2 \mathrm{~h}$, strong signal intensities can be observed with a saturation of the signal with increasing enzyme concentration, clearly demonstrating enzyme activity. Quantification of the detection limit revealed $5 \mathrm{zmol}(\sim 3000$ molecules AP) without incubation and $0.06 \mathrm{zmol}(\sim 35$ molecules AP) after a $2 \mathrm{~h}$ incubation.

The assay of inhibition for $\beta$-gal is shown in Fig. 5. As anticipated, it displays decreasing signal intensities with increasing inhibitor concentration. The same holds true for the dilution row assay, which displayed increasing signal intensities with increasing enzyme concentration (Fig. 6).

\subsection{Cathepsin D}

To apply the multiple spotting technique to more sensitive enzymes with medicinal relevance, we have also tested cathepsin D on microarrays. Cathepsin D is an acid protease, belonging to the peptidase family A1. It is suggested to play a role in the pathogenesis of sporadic Alzheimer's disease [22] and in the process of tumor invasion and metastasis of dif-

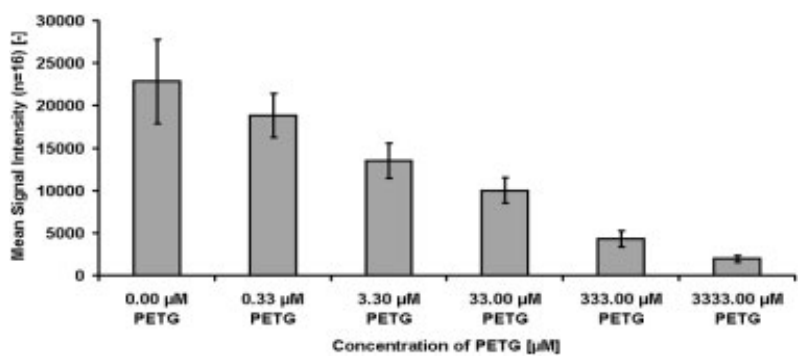

Figure 5. Assay of inhibition for $\beta$-gal. Mean signal intensity versus concentration of PETG diagram with standard deviation error bars for inhibition assay of $\beta$-gal. A dilution row of PETG was prepared ranging from $3.3 \mathrm{~mm}$ to $0.33 \mu \mathrm{M}$ PETG and applied to a microarray-based assay of $\beta$-gal. Scanning and analysis were performed without incubation. 


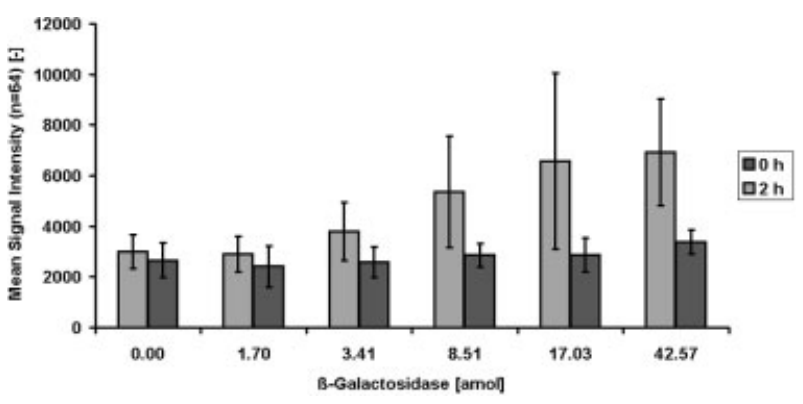

Figure 6. Detection limit assay for $\beta$-gal. Mean signal intensity versus activity of $\beta$-gal diagram with standard deviation error bars for the detection limit assay of $\beta$-gal. A dilution row ranging from 42.57 to 0 amol per spot $\beta$-gal was prepared and spotted onto a fluorogenic substrate. Scanning and analysis were performed without incubation and after $2 \mathrm{~h}$ incubation.

ferent types of cancer [23, 24]. Moreover, the measurement of cathepsin D activity can serve as a prognostic marker in breast cancer [25].

Using the multiple spotting technique, we were able to measure decreasing signal intensities with decreasing enzyme concentration (Fig. 7). An increase of signal intensity after incubation could be observed, which shifted the detection limit from $648 \mathrm{amol} / \mathrm{spot}$ without incubation to 464 amol/spot after an $1 \mathrm{~h}$ incubation. These results display a 10 to 15 -fold decrease of detection limit of the microarraybased approach in comparison to the microtiter plate [26]. Reasons for this decrease may be the superior sensitivity of the scanner or the limited diffusion possibility of the fluorogenic substrate, which enhanced the frequency of substrateenzyme interaction and hence promoted catalysis. However, since casein is not the optimal substrate of cathepsin D and was used due to hardware limitations, it can be expected that even better results can be obtained using an optimized fluorogenic substrate.

\subsection{Outlook}

Although unprecedented detection limits have been observed, an optimization of the methodology according to enzyme and substrate may allow even lower detection limits. An important point to consider in this context is the substrate concentration, which is a limiting factor in the experiments shown above and may have influenced the results by end-product inhibition. Furthermore, the use of optimized buffers or hygroscopic substance other than glycerol may enhance detection and hence provide better sensitivity. Another factor is the transfer of the compounds to the chip surface. While contact printing systems provide reliable deposition of compounds with varying properties, non-contact printing systems may be more adequate in some applications, since they provide more gentle handling of the substance to be spotted and especially for the substances onto which is deposited. As the microarray surface is not required for the immobilization of the enzymes, it is conceivable that other surfaces

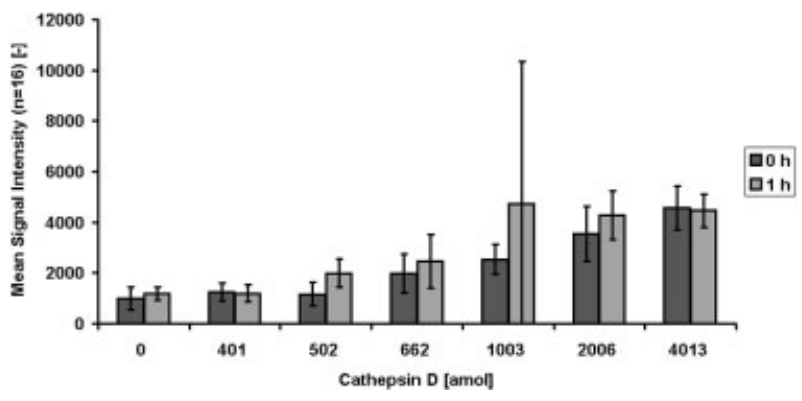

Figure 7. Detection limit assay for cathepsin D. Mean signal intensity versus activity of cathepsin $D$ diagram with standard deviation error bars for the detection limit assay of cathepsin D. A dilution row ranging from 4013 to 0 amol cathepsin $D$ per spot was prepared and spotted onto a fluorogenic substrate. Scanning and analysis were performed without incubation and after $1 \mathrm{~h}$ incubation.

such as matrices used for mass spectrometry can be applied as well. This would allow the readout of enzymatic reactions for which fluorescence-based assays are not available. Since the product is known, it can be used for calibration, thus facilitating the detection in a highly parallel fashion.

Areas of application for the enzymatic assay on the chip include the characterization of enzymes with regard to substrate specificity or activity. This approach is especially useful in metagenomics, which is currently seeking new enzymes with novel functionalities [27, 28]. In addition, assays can be performed on a large scale to screen for potent inhibitors or new substrates. Another valuable application is the amplification of enzymatic reactions using enzyme-antibody conjugates. Since the development of an amplification method for proteins comparable to PCR is not in sight, the screening of complex protein samples on microarrays requires a very sensitive detection procedure current microarray technologies cannot deliver. An enzymatic amplification of the signal as commonly applied in ELISA would therefore be desirable. Apart from fluorescent detection, chemiluminescent detection may be beneficial in some applications, which suffer from high background fluorescence. This approach could be especially beneficial in drug and disease screening assays and the optimization screening of enzyme mutants for biotechnology, both areas in which high-throughput is required.

\section{Concluding remarks}

Taken together, alkaline phosphatase, horseradish peroxidase and $\beta$-galactosidase were tested on a microarray with regard to inhibition of enzymatic action and determination of the detection limit. All three enzymes catalyze different reactions, such as oxidation, dephosphorylation and transgalactosidation and showed specific inhibition using the respective inhibitors. While displaying comparable detection limits with regard to activity, an unprecedented shift of sensitivity was observed with a limit of down to $0.06 \mathrm{zmol}$ 
( $\sim 35$ molecules) per spot. To anticipate further areas of application with more sensitive enzymes of medicinal relevance, cathepsin D was tested and a 10 to 15 -fold more sensitive detection was observed using a suboptimal substrate. We have shown that enzymatic assays can be transferred to the microarray format by application of our MIST approach. Finally, we have demonstrated that the approach allows the detection of minute amounts of enzymatic activities using only standard microarray equipment.

\section{References}

[1] Glökler, J., Angenendt, P., J. Chromatogr. B Analyt. Technol. Biomed. Life Sci. 2003, 797, 229-240.

[2] MacBeath, G., Schreiber, S. L., Science 2000, 289, 1760-1763.

[3] Cohen, C. B., Chin-Dixon, E., Jeong, S., Nikiforov, T. T., Anal. Biochem. 1999, 273, 89-97.

[4] Houseman, B. T., Huh, J. H., Kron, S. J., Mrksich, M., Nat. Biotechnol. 2002, 20, 270-274.

[5] Zhu, H., Klemic, J. F., Chang, S., Bertone, P. et al., Nat. Genet. 2000, 26, 283-289.

[6] Angenendt, P., Nyarsik, L., Szaflarski, W., Glökler, J. et al., Anal. Chem. 2004, 76, 1844-1849.

[7] Chen, G. Y., Uttamchandani, M., Zhu, Q., Wang, G., Yao, S. Q., Chembiochem 2003, 4, 336-339.

[8] Gosalia, D. N., Diamond, S. L., Proc. Natl. Acad. Sci. USA 2003, 100, 8721-8726.

[9] Schweitzer, B., Roberts, S., Grimwade, B., Shao, W. et al., Nat. Biotechnol. 2002, 20, 359-365.

[10] Shao, W., Zhou, Z., Laroche, I., Lu, H. et al., J. Biomed. Biotechnol. 2003, 2003, 299-307.

[11] Angenendt, P., Glökler, J., Konthur, Z., Lehrach, H., Cahill, D. J., Anal. Chem. 2003, 75, 4368-4372.
[12] Angenendt, P., Wilde, J., Kijanka, G., Baars, S. et al., Anal. Chem. 2004, 76, 2916-2921.

[13] Soldatov, A. V., Nabirochkina, E. N., Georgieva, S. G., Eickhoff, H., BioTechniques 2001, 31, 848-854.

[14] Angenendt, P., Glökler, J., Methods Mol. Biol. 2004, 278, 123 134.

[15] Angenendt, P., Glökler, J., Murphy, D., Lehrach, H., Cahill, D. J., Anal. Biochem. 2002, 309, 253-260.

[16] Angenendt, P., Glökler, J., Sobek, J., Lehrach, H., Cahill, D. J., J. Chromatogr. A 2003, 1009, 97-104.

[17] Ortiz de Montellano, P. R., David, S. K., Ator, M. A., Tew, D., Biochemistry 1988, 27, 5470-5476.

[18] Deininger, M. H., Meyermann, R., Histochem. Cell Biol. 1998, 110, 425-430.

[19] Fiering, S. N., Roederer, M., Nolan, G. P., Micklem, D. R. et al., Cytometry 1991, 12, 291-301.

[20] Burke, B. J., Regnier, F. E., Anal. Chem. 2003, 75, 1786-1791.

[21] Hadd, A. G., Raymond, D. E., Halliwell, J. W., Jacobson, S. C., Ramsey, J. M., Anal. Chem. 1997, 69, 3407-3412.

[22] Schulte, T., Bohringer, S., Schols, L., Muller, T. et al., J. Neural Transm. 2003, 110, 749-755.

[23] Castilla, E. A., Prayson, R. A., Abramovich, C. M., Cohen, M. L., Am. Clin. Path. 2003, 119, 123-128.

[24] Kanber, Y., Demirbag, N. R., Sam, A. D., Aydin, N., Int. J. Biol. Markers 2002, 17, 165-168.

[25] Rochefort, H., Garcia, M., Glondu, M., Laurent, V. et al., Clin. Chim. Acta 2000, 291, 157-170.

[26] Jones, L. J., Upson, R. H., Haugland, R. P., Panchuk-Voloshina, N., Zhou, M., Anal. Biochem. 1997, 251, 144-152.

[27] Schloss, P. D., Handelsman, J., Curr. Opin. Biotechnol. 2003, $14,303-310$

[28] Gupta, R., Beg, Q. K., Khan, S., Chauhan, B., Appl. Microbiol. Biotechnol. 2002, 60, 381-395.

[29] Huang, R. P., Huang, R., Fan, Y., Lin, Y., Anal. Biochem. 2001, $294,55-62$. 